\title{
REASON AND REASONING: TRUTI, TRUTHFULNESS AND INTEGRITY
}

In the time of Descartes, philosophers on both sides of the English Channel inhabited the same universe of discourse, were concerned with the same range of questions and argued about them in mutually intelligible ways. Descarte's own central concern, of course, was questions of certainty, knowledge and truth; as Anthony Kenny has put it, "his whole philosophy can be described as 'the search for truth'." Within the world of analytic philosophy students of my generation were brought up with very much the same view of what philosophy should be about. Given the basically empiricist commitments of our training, however, we were unable to give much credence to the different claims made by different philosophers on the alleged basis of direct rational insight, but were taught to insist on conceptually or logically compelling demonstration of the soundness of explicit argument structures. Reason in philosophy was thus for us essentially a matter of argument and careful conceptual analysis. Good students sought to mark themselves out by their ability to detect and to criticize arguments in the texts that they had to study and to produce effective arguments of their own; these were, and to a very large extent still are, the main criteria (apan from a proper knowledge of their material) on the basis of which they must expect to be assessed in examination at whatever level. But when, in the hope of challenging our own established authorities, we turned to the locally ostracized writings of so-called 'continental' philosophers, we were in general boih baffled and frustrated to find ourselves unable to work out just what they were trying to argue.

This assumption - that philosophical productions were to be judged on the basis of the explicit arguments and argument structures that they contained- was fundamental to our understanding of the very nature of philosophy. We were familiar, of course, with disagreements as to the acceptable limits within within different types of such structures were properly to be recognized as such; were the proper criteria to be recognized as those of formal logic alone, or should we be ready to recognise a whole variety of modes of informal logic, of contextual implications, of material rules of inference, of conversational implicatures or whatever? But all were agreed that without some such controlling framework of rules ol argument, anyone might sny or write anything that came into his or her head in an entirely arbitrory manner; for nothing would count as a better or worse reason for any on allirmation rather than another. This alone goes a long way towards explaining why we felt in general so uncomfortable with, for example, texts which started out with much talk of 'the phenomenological method', but then proceeded to present a series of descriptions of one sort and anotler without, so far as we could detect, also producing any methodically set out arguments designed to justify those descriptions as correct or true.' (As any sort of overall assessment of 'continental plilosophy' this was, of course, no better informed or more generally illuminating than the similarly summary and dismissive asssessments that most "continental' philosoplers of that time

I As Hesserl himself characteristically put it in his Preface to the English edition of Ideen, "Eidetic phenomenology is festricted in this book to the realin of pure eidetic "description', that is to the realm of essential structures of transcendental subjectivity immediately transparent to the mind... Thus no attempt is made to carry out systematically the transcendental knowledge that can be obtaint through logical deduction." Edmund l fusserl, Ideas: General Imroduction to Pure Phenomenologn, translated by W.R. Boyce Gibson (George Allen and Unwin. London, 1931), p.12. 
would have provided of the sort of philosophy that was then being produced in the so-called analylic world.)

If one conceives of the rationality of philosophical discourse as thus depending on line conceptual distinctions and on the logical status of the argument structures around and on which it is built, and of the order of these arguments as being deternined by properly atemporal rules of inference, whether formal, informal or material, one may well find dificulty in appreciating what is going on in the texts of those for whom the rationality of such discourse is to be understood essentially in terms of the actual practice of reasoning. By this expression I mean something other than 'the practice of reason' understood as referring to the working out of some sort of principle of rationality in human history in general. To this we infant analytic phisolophers would have found it dificult to attach any clear sense. Brought up, as in general we were, to distrust any talk of abstract general agency, it seemed clear to us that reason as such 'does not do anything, it is people who do things more or less rationally, as the cases may' be. By 'the actual practice of reasoning', however I refer simply' to the fact that the production and presentation of rational argument has to be recognised as constituting a temporally ordered, and hence causally structured, sequence of events, even if what the sequence issues in is the production of an atemporally; logically ordered structure of argument. Not even the most analytically minded of philosophers, would find any difliculty in recognising this fact. The difficulties may start to arise, however, when one comes to the question of the implications that this recognition may -or may not - have for one's own understanding and on-going pursuit of one's own philosophical activity.

That the production of any form of discourse whatsoever, of any sort of text, is bound to have all sorts of causal effects on those to whom it is addressed, or ivho, not being addressed, nevertheless intercept it, over and above those of the communication of whatever may be its rational or explicit informational content, is, of course, extremely well known. The point is not infrequently made by saying that any text whatsoever may be read as a form of literature. Traditionally, of course, philosophers, unlike the producers of other and perhaps grander forms of literature, have been not so much concerned with the varied concomitant effects that their actual speech or writing might produce in their readers or listeners as with the 'rational' structure and drift of their arguments. In this analytic philosophers hive in the main kept much closer to the classical tradition than many of those whom they would regard, rightly or wrongly, as most characteristically' 'continental' among their collengues. By this 1 do not mean, of course, that philosophers have not in general been concerned about their style. l3oth Hume and Kant certainly were; so, among more recent philosophers, were both Gilbert Ryle and Jolnn Austin. But neither of them would have thought that either the validity of their arguments or the truth of their conclusions were in any way' dependent upon the 'literary' or 'rethorical' qualities of the language in which they were expressed. But this is to take for granted the possibility in principle of establishing some clear distinction between the argument content or message of any given text and the medium of its expression. Or, to put the point another way, it is to take for granted the possibility of establishing some clear and workable distinction between meaning and force.

That any adequate overall theory of language must allow for some broad distinction between meaning and force may be taken as calling for no further argument here; in pointing out that in standard contexts the primary force tor my' uttering sucli an expression as 'Sit down' is eflectively the same as would be that attaching to my' uttering 'Asseyez-vous', it is clear that in this context $I$ am not actually telling or inviting anyone to sit down, but also that it would be 
impossible for me to provide this piece of linguistic information if those expressions did not bear the same meaning in the contexts both of use and of mention. It is equally clear that the standard prescriptive force of the use of such expressions is closely bound up with whatever exactly we may deline as their meaning; and clear more generally that learning a natural language must always involve learning both the meanings of its terms in their various combinations and the forces attaching to their use in at any rate the most common and standard contexts. $A$ s Jacques Derrida has put it somewhere "Force is the other language williout which the latter would not be what it is."

So what is one to be understood, what is one to understand oneself, as trying to do in producing philosophy - philosophical texts, plilosophical lectures, philosophical teaching, philosophical reflection, whether solitary or in communing with others, in short in producing philosophical discourse? Is one seeking rationally convincing answers to rationally formulated questions, answers that may carry satisfactory' conviction to oneself or secure, maybe. the ratiomal assent of others? Or is one trying to persuade, to modify or to sustain certain dispositional beliefs and other attitudes by all the devices at one's disposal? Or, to put the point another way. is on simply concerned with conceptual content and the realions (essentially timeless, as one might say) between meanings, relations of implication, entailntent or exclusion by virtue of contradiction, or is one concemed with all the (causal) forees at work in the place and time of one's arguments? Even the most rationally minded of analytic philosophers would readly acknowledge that such forces must be at work whenever they give a tutorial or a lecture, publish a text or othenvise engage in the business of 'doing philosoply'. But most would insist that it was no part of their business as philosophers to try to take account in the shaping of their teaching, writing or lecturing of any such causally contingent and, as such, "non-rational' forces.

None of this is to say that there have not been significant attempts on the part of ' $A$ ngloSaxon' philosophers to provide causal analyses of belief, of meaningful signs or of the ways in which intentions or reasons may be understood as efficient causes of events. There are also examples of pliilosoplters, prominent within the analytic lield, who quite explicilly set out to inlluence those to whom they address themselves not so much by the logically constraining force of their arguments as by nudging them into addressing certain problems or puzzles from a different perspective. Sucl philosophers have characteristically proceeded not by selting out theses and seeking to establish them as true on the basis or rationally compelling argument, but by encouraging people to look at matters in such and such a way ratler than in some olher. But, it is fair to say, for the most part this intellectual therapy proceeds by raising questions and adducing considerations designed to cast 'rational' doubt on the temability of long-held assumptions and to incite to the elaboration of fresh conceptual approaches, that is to say by oflering fresh material for discursive thouglt. And to the extent that the characteristic style of writings in the manner of, say, the later Wittgenstein, is to be considered as integral to the exercise of the philosopher has proven to constitute an exception that the world of analytic philosophy has in general lound hard to digest.

'To sum up this stage of my argument, lien: - It would occur only 10 a liny minority of philosophers working within the tradition within which I was myself brought up to try and construct their lectures or their texts in the light of such awareness as they might have of the probable wider causal impacts of ther 'speech performance". Or if they did so, it would be als they' would be, as they would see it, with other than philosophical purposes in view. Rational arguments, as we have noted. may be checked for their validity; and il valid, they will be so universally. The atemporality, the contingent particularity and the causal situatedness of ("practical") 
reasoning. The criteria by which the use of performative forces may be assessed are accordingly altogether different; they may be appropriate or inappropriate, successful or unsuccessful, or, as Austin might have said, happy or unhappy, depending on the particular contingent purposes and circumstances of their employment. Of course, if I, qua analytic philosopher, want to ensure the best possible chances for a successful communication of my views on how the arguments concerning some particular problem should go, then, rather than thinking of myself as addressing an imaginary 'ideally rational audience', 1 have to think of the likely reactions of my actually given audience or readership to one way of putting them rather than another. What may come across as clear and interesting (or perhaps even subversive) in one context may be obscure and merely boring in another, and I should be foolish not to take account of such things. But this is still in effect to think of the medium as simply' instrumental to the successful transmission of the message, and hence of the message as in principle wholly disentanglable from it.

What happens, though, if I start to take seriously the thought that no-one could ever -in principle- either transmit or receive a message that was not encoded in some particular historically contingent medium? If I remind myself of the irrationality of not taking, such account as I may of the context in which I am thinking and working, of the forces that must play tupon my own efforts, including those which are built in to the accepted meanings of the very mediun or language of may own thinking, as well as those which, through the contingently associated effects that they may have on my interlocutors, must play their part in shaping the message which actually gets through? At this point I may find myself caught by the awareness of a possible conflict between two or even three dilferent ends that up to now may have indistinguishably implicit in my philosophical undertaking, that of building a valid rational argument logically sufficient to establish the conclusions towards which 1 have been arguing as proven and those of securing 'your' assent to those conclusions and, more generally, 'your ' reception of my discourse as pertinent, interesting, well presented and strongly rooted in a cultivated knowledge of the relevant background and context -in short, as Austin might lave put it, of securing a certain sort of uptake. And 1 may conclude that, since what I have taken to be my concern with the rational working out and communication of the views that 1 hold to be correct can only find practical expression as reasoning and the altempted bringing about of apprupriate states of mind and/or belief in my readers or listeners, the only 'rational' way of proceeding must be by using the means best calculated to bring about these ends (without necessarily doing anything to hide from my audience (or myself) the nalure of the means that 1 an using).

All this, it goes without saying, constitutes only the barest outline of an argument that may lead the philosopher who follows it to bring back its conclusions to bear upon his own plitosophical enterprises as he shapes and pursues them; and, in so doing, to present his 'performance' by setting it within a play of protective forces such as may be provided by a marshalling of appropriate references to well-known authors and texts, which may fulfil the function of providing an effective screen of learning, culture and authority. I do not, of course, mean to suggest to any particular philosophers that they must have had some such argument somehow explicitly in mind. Indeed, the undermining of what may be called reason's confidence in its own authority has many other sources. There have been after all a whole sequence of "masters of suspicion", who in their different ways have sought to show us how and why, when we may have thought that we were reasoning, we were almost certainly "really" doing something else. (Nany of the reasons given for this mistrust of reason and rationality - and they are typically' put forward as reasons - lave their roots in the arguments whereby kant looked to work his way fret of the essentially insoluble problems inherent in the Cartesian assumption of our power of direct 
and immediate insight into the fact and contents of our own conscious experience as thinking beings.) Ther is no doubt something prima facie paradoxical about an argument that, when it turns back upon itself, ends up by undermining its own very status as argument; but paradoxical or not, its seriousness is not to be underrated. However, it is not to my present purpose to rehearse this argument once again; nor, for that matter, to seek to assess the rational checkability and rival merits of the very diflerent ways of presenting a position, or of justifying a description, other than those based on explicitly formal or informal logical inference, sucl as maly consist. for example, in setting it against the background of certain historical precedents rather than of others and in thus altering the interpretive light in which it is to be seen; (one recognisably rational way of checking such interpretive realignments might be by further close examination of whatever historical texts are in question, another, no doubt, by the relevant citing of alternative and competing precedents). What is important to note is that these are significantly difterent discursive practices, the skills and habits of which require and derive from dillerent formative habits of disciplined training and thought? The question which concems me here is raller that of what difference it might make to one's view of the standards to be observed in one's philosophical work, once one looks upon what on is producing, in and through one's philosophical reasoning, as first and foremost a certain kind of spatio-temporally situated performance rather than as an essentially atemporal structures of purely rationally ordered argument.

If one takes it to be a constilutive presupposition of discourse in general, be it written or spoken and be it directed to oneself or to others, that its governing purpose or point must lie in the production of certain primarily communicative effects, then the overriding concern of those who persist in believing philosophy to be an essentially rational and truth-orientated endeavour, must shift from one directed primarily to the validity of their argument structures or the truth of their theses to one directed primarily to the truthfulness of their attempts to communicative and to the integrity of their argumentation. This is in no way to deny that truth and truthfulness are interrelated concepts, and that $I$ cannot be trutliful in my performance if I am knowingly atvare that it contains anything false or that my arguments contain some hidden fallacy. But to be truthful in the saying of whatever one says and in the writing of whatever one writes is to be concerned with the establisment of true beliefs in one's partners in discourse; for this it is not sufficient simply to believe that one's arguments validly entail 'the strict truth' of what one is saying. If universality is the proper mark of valid argumentation, it is not sufficient to guarantee the truthfulness of one's saying or writing in the always particular context of communication. For communication is necessarily a relationship between at least two terms. even in the limiting case where one is in effect trying to communicate with one's own present or future self. There has to be some element of untrutlifulness about any apparent attempt at communication, if it includes no ellort to take account of the conditions or receivability of the intended message. ${ }^{3}$ Broadly speaking, these conditions may relate, (i), to the receiver's capacity for picking

2 There is also, of course, a powerfil current of thought, which likewise perlaps has its distant roots in Kant and his development of the distinction between Reason and Imagination, uhich ends up by seting Reason as essentially hostile to any form of creative life or thought. For sxample, in their l.e mythe nazi (pp.36/37) I'hilippe Lacoue-Labartle and Jean-Luc Nancy quote Heidegger's afianation that "Reason, to which so much importance has been attached over the centuries, is the most unremitting enemy of thought."

3 This point las beell amply' recognised by a number of recent politcal philosophers and plilosophgers of education working in the analytic tradition in its implications for what has come to be recognised as lic sphere of public reason within a pluralistic democracy, but as yet less so, it wotld seem in its potential rellexise implications for the manner of their own plilosoplical discourst. 
up and interpreting messages, and, (ii) to those assumptions which receivers may reasonably regard themselves as entitled to make, whether by virtue of some mutually recognisable convention or of some feature contingent on the particular context, as to the intentions with which the sender has transmitted his or her message. Broadly speaking again, the first set of conditions may be thought of in terms of tle truthfulness of transmission and the second in terms of the integrity of the transmitter.

(i) Truthfulhess. Communication can be truthful only in so far as the sender of messages transmits what he or she in fact believes to be true. Everyone knows, however, that there are many ways in which it is possible to make deceptive use of arguments leading validly enough from true premises to true conclusions in order to obfuscate or mislead. If one ivishes to assure truthful communication, one has to make as sure as one can that the language and manner of one's communication is properly adapted to what the audience may be capable of understanding, not only by way of capturing its meaning but also of reacting appropriately to the forces that its terms may carry both in general and in the particular context of the communication in question. It is notoriously often possible to turn aside embarrassing enquiries by providing a host of true statements on only marginally relevant issues. Again, if I have acquired a sulitciently solid reputation as a liar with a given person or body of persons, it may very well be that my best chance of leading them away from the truth may be simply by stating it very empatically. In other cases, relations between me and my audience may be such that there is no way in which I am going to be able to convince them of what I am nevertheless convinced to be true. In such cases, I have somehow to re-establish certain basic conditions of trust, the basic conditions of truthful communication, before I can hope to be able to convey my message; to act as if these conditions are fulfilled, when I have every reason to know that they are not, is not to act in good faith. In cases where the sender of a message has good reason to believe that his intended audience will almost certainly take as true whatever happens to be the opposite of what he says, there is even a certain paradoxically limiting sense in which truthfulness, as the effective communication of what the sender believes to be the truth, may best be secured by asserting its very opposite.

In short, if, indeed, the truthfulness of an act of communication lies in the seriously conceived intention of would-be communicators to secure the uptake of that which they believe to be true, it must depend upon their readiness and ability to adapt their message to the contingently' particular conditions of its context of transmission. Thus, if truth aspires in some sense to the universal, truthfulness can not, but is bound in its expression - and if it is to be true to itself, as one might say, must recognise itself as so bound- to the particular.

(ii) Integrity. A number of those who have written on the 'transcendental presuppositions' of standard discourse (Paul Grice, Patrick Nowell Smith) have pointed out that the hearer or reader is normally entitled to presume that the speaker or writer himself believes such assertions as he may be led to make to be true; in other words, that standard discourse proceeds on the assumption of the truthfulness of those who speak. Learning to speak necessarily includes lessons in the recognition of those conventions which serve as signals that a particular discursive context is to be taken as in some way non-standard and that this assumption (of truthfulness) is not to be taken as holding. For example, when young children are first taken to the theatre, they not infrequently take the actors actually to be the characters that thye are representing and, hence, nctually to believe, in propia persona as it were, the assertions provided for them by the script, but it is clear that no experienced theatre-goer would ever make such a mistake. 
To assume the trutliulness of one's interlocutor is, however, in eflect to make at the same time a certain number of further assumptions about him. It someone tells me of lis belief in the validity of a certain line of argumentation and in the truth of the conclusions to which it leads, I am less likely' to lend credence to him if he has only yesterday assured me of a contrary belief; and even less likely to do so, if I see no reason to suppose that he is tomorrow likely to believe in the validity of the same set of arguments or in the truth of the same conclusions. It is not so much that I necessarily be should led to suspect him of dissembling or of a lack of truthliulness as that to lay claim to a belief is to commit oneself in certain ways, which is in turn to presume to a certain kind of stability through time. This stability is not to be confounded with a stolid cognitive immobility. There are many propositions whose truth I should now be prepared to affirm while being equally ready to acknowledge that $1 \mathrm{might}$ quite possibly come sooner or later to clange my mind. But for my present abjirmation to count as one of a serious belief, there has to be a reasonable assumplion dhat, should 1 in fact come to change my mind, if will only be on the basis of some equally serious reconsideration of the grounds on which my previous belief was based. This, of course, is also to presume an appropriate weight of continuity between my present self as believer in the truth of $p$ and my lypothetical future self, who may have come, on the basis of a certain follow-through of rellection, 10 reject that beliet:

These presumptions may very appropriately be regarded as amounthing in sum to a presumption of integrity. "Integrity" is a term that has recently seen a remarkable degree of not always very precise public use. The Oxford English Dictionary provides us with the following account: $\cdots 1$. The condition of having no part or element wanting; unbroken state; material wholeness, completeness, entirety. 2. Unimpaired or uncorrupted state; original perfect condition; soundness, 3.a. Innocence, sinlessness. b. Soundness of moral principle; the character of uncorrupted virtue; uprightness, honesty, sincerity." It is to be noted, incidentally, that none of the quotations given to illustrate these different usages date from later than 1678. By way of comparison with the French, Le Grand Robert gives us: "'l. Elat d'une chose quiest dans son entier. complete, intígrale... qui es donnéc intacte, inaltérée... (Intégralité est plus qualicatil qu intégralité, reservé gentralement à ce qui est mesurable). 2. Etit d'une personne integre. Voir honnetete, incorruptibilits, justice: probitc..." The underlying theme of both accounts is that of an original wholeness, and the consequential theme of moral soundness is that of someone who is, as the English idiom has it, 'all of a picte'. whose fundamental honesty and reliability spring from the fact that he (or she) has no hidden discordances such as 10 make for an unpredictable changeability over time or from one context to another. In highlighting the reference to origins both dictionaries are doubtless lailhful to the origins of the coneept of integrity itselt: Nowadays, however, it would probably be more common to think of the wholeness of integrity' as a task or a goal al which to ain, even as one knows that there can be no possible assurance that one has ever definitively adtieved it. (Nor has it necessarily to be supposed that a man of integrity will never dissemble. $A$ secret agent, for eximple, may be prolessionally commited to a lifi of deception, but such commitments may be entered into on the basis al a more fundanental and persisting commitment that provides the framework of constancy to his life.) There is. as we have just noted, no necessary loss of integrity involved in the more fact of clanging either one's mind or one's tactics, so long as the change is made on seriously rellected grounds; on the contrary; a min of integrity mus be prepared to change his mind when confronted with convineing evidence that he had previously been mistaken. The soundess and stability of integrity are not to be conlised with mere immobility or rigidity as such: lley are rather a malter of constancy of underlying principle and purpost. ol' steadiness of direction, and 
of reliability through changing circumstance -in other words, of a certain self-integration (or what Kant might lave called synthesis) through time.

Seen in this light, it is clear that the conditions of truthfulness and those of integrity are closely bound up with each other. The truthful communicator, he or she who is concerned to secure uptake to what he believes to be a true message, based on a set of properly valid arguments, will seek to encode his message in terms to which his audience may be expected to respond in the appropriate manner. But he can only count on securing this response in so far as his audience take him to be a communicator of integrity, that is to say someone who not only secks to communicate what in the moment he believes to be true, but someonewho is not lightly going to sivitch to another view the moment after, someone who remains reliably himself or herself through time, someone whose successive stages of life, whose different aspects of personality and different relations with different people, together with his conception of the norms by which such relations should be governed, are so self-integrated as to constitute a coherent, stable and reliable whole.

The truthful communicator, the, will seek to adapt the terms of what he has to say to the needs of particular context of its intended or likely reception. It may be that, as in the case of my own philosophic upbringing, what is thus called for is explicitly set out argument, where one can be reasonably confident that its recipient will automatically seek to distinguish the manner of its setting out from its cognitive content and set it aside as so much incidentally pleasing or displeasing decoration. But there may, no doubt, be other and locally more effective ways of setting out, in the sense of displaying, a plilosophical position - by locating it in relation to other historically familiar positions by way of suggestive reference and quotation, both directly and also indirectly by one's own choice of expression, and in relation not only to other philosophical positions but in relation also to the visions expressed in otler forms of literature and even, indeed, of art more generally. To display a position in this way may also be both to provide a form of justification for it, by thus showing just how we it fits in to a recognisable pattern, and a form of authentication of one's own right to speak with authority by providing the evidence of one's own learning.

So, to return to the themes of our starting point, one way of trying to make sense of what, when one looks at it in the light of earlier listory, must strike one as the quite extraordinary gulf of mutual incomprehension and disdain that has come to divide the world of western pliilosophy, and which is only now starting to be tentatively and partially rebridged, is to ste it as resulting from two different claains of reactions and counter-reactions to a line of an argument that has its roots in the peculiar form of Transcendental Dualism to which Kant was led as he attempted to find a way of avoiding the paradoxes to which his Cartesian predecessors had been drawn. Both chains start from a sense of the unacceptability' of Transcendetal Idealism's strictly unintelligible but equally strictly unavoidable disjuntion of the human subject into its plrenomenal and noumenal aspects.t Very broadly speaking. the philosophers of the English-speaking world reacted by simply withdrawing from what they saw as an uncontrolled and uncontrolla-

4 Cf. Kant's own characterisation of the situation at he end of his Groundwork of the Metapliysic of Murals: "Thus, while we do not comprehend the practical unconditioned necessity of the moral imperative, we do comipreliend its incomprehensibility. 
ble mess of theoretical speculation, while their 'continental' colleagues reacted by trying to push the Kantian arguments on still further - beyond the point at which they saw Kant as having got stuck and in the end, as we have seen, to a point where rational argument ends up by undermining itself (and thus the whole characteristically Kantian thesis of Reason's necessary respect for itself) and by tranferring the emphasis to the non-rational aspects of the overall activity of reasoning. At this point, the criterial norms by which the formal products of reason are to be assessed tend to give way to those by which one may assess philosophical discourse as literary, political or some other pertinent form of performance.

In the end, however, we have to remember that the two perspectives, that of Reason as the power to create and to assess cognitive argument structures and that of reasoning as the staging of a complex performance are, whatever the tensions between them, fundamentally interdependent. Whoever would be truthful in their performance must retain their grip on the distintion between truth and falsity and on the relation, whatever its proper formulation, between truth and meaning; whoever seeks to communicate with integrity must retain their grip on the distinction between valid and invalid argument. It is true, of course, that we can never hope to construct or encounter a universally valid argument that is not couched in the terms of one particular speecl community or another, terms that will carry all their own locally peculiar illocutionary and potentially perlocutionary forces. But this, it would seem, is a tension from which we may aspire, but should not hope to escape. Indeed, we may end up by finding ourselves unable to maintain sufficient grip on the crucial structures of validity and truth if the prevailing culture does not once agnin encourage us as philosophers to insist, within the contexts of our philosophical performances, on being allowed to hold at bay, even as we acknowledge their existence, the impacts of the 'illocutionary' and 'perlocutionary' forces that such performances may always carry or take on in the course of our active exchanges. 